\title{
REFLEXÕES SOBRE O MODELO DE AQUISIÇÃO DE SEGUNDAS LÍNGUAS DE STEPHEN KRASHEN - UMA PONTE ENTRE A TEORIA E A PRÁTICA EM SALA DE AULA
}

\author{
MARÍLIA OLIVEIRA VASQUES CALLEGARI \\ USP
}

\begin{abstract}
RESUMO
Baseando-se em algumas das principais idéias levantadas pelo lingüista norte-americano Stephen Krashen em seu Modelo do Monitor, este artigo se propõe a analisar criticamente alguns conceitos presentes nessa teoria e, principalmente, verificar de que forma o professor de línguas estrangeiras pode beneficiar-se das cinco hipóteses levantadas ao longo de seu estudo, durante as aulas de língua estrangeira em contextos formais de aprendizagem. Palavras-chave: modelo do monitor; aprendizagem; língua estrangeira.
\end{abstract}

\section{RESUMEN}

Basándose en algunas de las principales ideas del lingüista estadounidense Stephen Krashen en su Modelo del Monitor, este artículo se propone a analizar críticamente algunos conceptos presentes en esa teoría y, principalmente, verificar cómo el profesor de lenguas extranjeras puede valerse de las cinco hipótesis presentadas a lo largo de su estudio, durante las clases de lengua extranjera en contextos formales de aprendizaje.

Palabras-clave: modelo del monitor; aprendizaje; lengua extranjera.

É inegável a influência do lingüista norte-americano Stephen Krashen nos estudos e pesquisas referentes à aquisição/aprendizagem de segundas línguas ${ }^{1}$. Suas principais obras ${ }^{2}$ foram publicadas há cerca de vinte anos e são ainda hoje amplamente debatidas, tanto por adeptos às suas idéias como também por seus críticos. Seu modelo teórico, conhecido como Modelo do Monitor, desempenha importante papel nas pesquisas sobre aquisição de línguas estrangeiras. Não obstante, são poucos os estudos, principalmente em língua portuguesa, que se propõem a fazer uma análise crítica dessa teoria, relacionando-a ao trabalho efetivo do professor em sala de aula.

${ }^{1}$ O termo segunda língua (L2) será, neste artigo, sinônimo de língua estrangeira (LE), assim como o termo língua um (L1) equivalerá à primeira língua adquirida pelo indivíduo e será, aqui, sinônimo de língua materna (LM). Krashen prefere utilizar as expressões L1 e L2.

2 KRASHEN, S. Principles and Practice in Second Language Acquisition. Oxford, Pergamon, 1982.

KRASHEN, S. et alii. Child-Adult Differences in Second Language Acquisition. Massachusetts, Newbury House Publishers, 1982.

KRASHEN, S.; TERRELL, T. D. The Natural Approach: Language Acquisition in the Classroom. Oxford, Pergamon, 1983.

KRASHEN, S. The Input Hypothesis: Issues and Implications. London, Longman. 1985. 
CALLEGARI - Reflexões sobre o modelo de aquisição de segundas línguas...

Passaremos, primeiramente, a uma descrição e análise do modelo proposto por Krashen para, a seguir, deter-nos mais detalhadamente em cada uma de suas hipóteses. Tomaremos como contraponto à sua teoria as idéias do também lingüista americano Barry McLaughlin, que em seu livro Theories of second-language learning (1987) discute amplamente o modelo proposto por Krashen. Tentaremos, então, traçar algumas considerações sobre as implicações da teoria em sala de aula.

\section{O MODELO DO MONITOR}

O Modelo do Monitor (Krashen 1977,1982,1985³ ) está baseado em cinco hipóteses: A hipótese da distinção entre Aquisição e Aprendizagem

Para Krashen, há dois caminhos distintos no processo de apropriação de uma língua estrangeira:

a) AQUISIÇÃO: é um processo automático que se desenvolve no nível do subconsciente, por força da necessidade de comunicação, semelhante ao processo de assimilação que ocorre com a aquisição da língua materna. Não há esforço consciente por parte do indivíduo nem ênfase no aspecto formal da língua, mas sim no ato comunicativo em si. Para que ocorra a aquisição faz-se necessária uma grande interação do aprendiz com a língua meta. Um exemplo típico de aquisição é o caso dos imigrantes que chegam a um país cuja língua falada é diferente da sua e, por força das necessidades comunicativas, adquirem a língua local sem possuir nenhum (ou pouco) conhecimento formal e explícito sobre tal língua.

b) APRENDIZAGEM: é um processo consciente que resulta do conhecimento formal "sobre" a língua (Krashen,1985:1). Através da aprendizagem (que depende de esforço intelectual para acontecer), o indivíduo é capaz de explicitar as regras existentes na língua meta.

Para Krashen, a aprendizagem nunca se transformará em aquisição e, portanto, através da aprendizagem nunca se chegará a um nível de competência comunicativa que possa ser equiparada à de um nativo, o que ocorrerá apenas se houver aquisição. A situação de aprendizagem contribuiria apenas para um discurso pouco fluido, uma vez que os alunos estariam mais preocupados com a forma do que com a mensagem a ser transmitida ${ }^{4}$.

Não são poucas as críticas a essas concepções. Para McLaughlin (1987:21,24) a hipótese é falha desde o início uma vez que Krashen não define claramente os termos "aquisição", "aprendizagem", "consciente" e "subconsciente", tornando assim impossível determinar exatamente o que seriam "língua adquirida" e "língua aprendida". Além disso,

\footnotetext{
3 Neste estudo nos pautamos diretamente na obra The Input Hypothesis: issues and implications. New York, Longman, 1985.

4 Ao não reconhecer a aprendizagem como importante fator dentro do processo de conhecimento de uma LE, Krashen desconsidera por completo a interlíngua, o que, do nosso ponto de vista, é um caminho equivocado.
} 
embora Krashen relate algumas pesquisas feitas com aprendizes de língua estrangeiras, McLaughlin questiona a metodologia empregada na comprovação de que determinadas estruturas foram "adquiridas". Para o crítico, é muito difícil (ou praticamente impossível) para um falante de língua estrangeira reconhecer se, ao elaborar uma sentença, valeu-se de seu conhecimento gramatical da língua (rule) ou de uma intuição (feel). Não existem, segundo este pesquisador, mecanismos que consigam detectar essa sutil diferença.

Outro ponto que merece atenção é o que se refere aos dados coletados por Krashen. A maioria de suas pesquisas baseia-se apenas na produção (grifos nossos) de aprendizes de uma LE, o que faz com que Romeo (2003) questione:

\section{Uma estrutura pode ser considerada "adquirida" quando não há erros de compreensão? Ou deveria considerar-se adquirida quando há um certo nível de precisão na produção?}

Como Krashen não apresenta uma definição do termo "língua adquirida", não é possível saber se essa expressão se refere a níveis de compreensão, de produção ou aos dois. Além disso, esbarra-se na questão metodológica que envolve todo do modelo de Krashen. McLaughlin ressalta que ainda não existem evidências empíricas que possam comprovar a existência e o funcionamento dos dois mecanismos (aquisição e aprendizagem).

\section{IMPLICAÇÕES EM SALA DE AULA}

Talvez Krashen tenha explicitado o que muitos de nós, como alunos e professores de línguas estrangeiras, freqüentemente observamos: aprendizes que estão imersos num ambiente onde a língua estrangeira é falada constantemente e que têm necessidades reais de comunicação (alunos que fazem intercâmbio, por exemplo) aprendem tal língua com mais rapidez e fluência do que quem a estuda formalmente, no seu país de origem, ainda que por muitos anos. É sabido também que apenas o estudo dos aspectos formais de uma língua não resulta em uma competência comunicativa global ${ }^{6}$, daí o insucesso atual de metodologias voltadas apenas para a gramática e a tradução quando se pretende, com elas, atingir tal competência. Concordamos também que muitas das regras que aprendemos, e sabemos "de cor", por vezes não são aplicadas no momento da produção de textos (orais ou escritos) em língua estrangeira.

Assim, somos levados a crer que realmente há dois processos distintos no momento em que alguém se aproxima a um idioma estrangeiro: um no qual são internalizadas certas estruturas da língua sem que tenham sido estudadas formalmente, decorrente apenas da exposição do indivíduo a ela, e outro no qual há um esforço intelectual para compreender o funcionamento da nova língua, como as regras de sintaxe ou o novo vocabulário.

${ }^{5}$ Esta tradução, como todas as demais, foi feita livremente pela autora. Original: "Is a structure 'acquired' when there are no mistakes in comprehension? Or is it acquired when there is a certain level of accuracy in production?"

${ }^{6}$ Entendemos por competência comunicativa global o conjunto das subcompetências gramatical, sociolingüística, discursiva e estratégica, conforme definido por Canale, 1983 (apud LLOBERA, 1995, p. 14) 
CALLEGARI - Reflexões sobre o modelo de aquisição de segundas línguas...

O que ainda nos causa certa dúvida é o fato de que, para Krashen, a aprendizagem nunca se transforma em aquisição. Muitos de nós devemos ter tido a experiência de memorizar quadros de conjugação verbal e listas de vocabulário, por exemplo, e perceber que a performance melhorava após essa prática, o que nos leva a supor que, de alguma forma, o estudo formal acaba por internalizar-se em algum momento (aquisição). Além disso, a experiência como estudante e como docente de língua estrangeira nos permite afirmar que mesmo encontrando-nos em situações de aprendizagem, em um dado momento esta se transformou em aquisição, posto que a nossa fluência - assim como a de alguns de nossos alunos - permitiu alcançar a competência comunicativa global.

A conseqüência mais grave ao crer que a aprendizagem não se transforma em aquisição é pensar na função do ensino formal de línguas, seja em escolas de idiomas seja em escolas regulares. Estariam esses cursos fadados ao total insucesso? Para Krashen sim, caso o foco fosse a todo o momento o aspecto formal da língua e não houvesse exposição do aluno a mostras significativas da língua alvo. No entanto, como veremos na hipótese a seguir, o conhecimento gramatical cumpre, dentro da teoria, uma função importante no processo de aquisição e não deve, portanto, ser banido.

\section{A hipótese do Monitor}

Para Krashen, a habilidade em produzir sentenças em língua estrangeira é decorrente da competência adquirida. No entanto, o conhecimento consciente das regras gramaticais (aprendizagem) tem também uma (e única) função: atuar na produção dos enunciados como um monitor, um corretor, modificando-os caso não estejam de acordo com as regras aprendidas. Ou seja, a produção criativa, surgida como decorrência do processo de aquisição, é corrigida e alterada com base no conhecimento consciente das regras da língua estrangeira em questão.

Para Krashen (1985:2), o Monitor somente entrará em ação se duas condições básicas estiverem presentes:

a) o falante precisa querer corrigir-se, ou seja, o foco deve estar na forma;

b) o falante deve conhecer as regras.

Para McLaughlin, esta hipótese apresenta-se ao menos incompleta. Krashen descreve a atuação do Monitor como um corretor que atua antes ou após a produção de um enunciado pelo aprendiz, mas omite-se, mais uma vez, com relação à função do Monitor no processo de compreensão de enunciados. Ou seja, muitas vezes não nos valemos do conhecimento de regras gramaticais para entender determinadas frases em língua estrangeira? O conhecimento de determinadas regras morfológicas, sintáticas, semânticas, fonéticas e/ou contextuais não nos facilita a compreensão de palavras desconhecidas, por exemplo? A teoria de Krashen não considera esses questionamentos.

A comprovação empírica desta hipótese também parece bastante distante já que, conforme comentado anteriormente, resulta muito difícil determinar quando alguém está empregando uma regra conscientemente e quando isso não ocorre. 
IMPLICAÇÕES EM SALA DE AULA

A hipótese do Monitor traz implicações significativas para o aprendizado formal de línguas estrangeiras. A freqüência de utilização do Monitor nos aprendizes pode variar bastante, assim como seus benefícios. Para Schütz (2002),

\begin{abstract}
Os efeitos deste monitoramento sobre pessoas com diferentes características de personalidade serão vários. Pessoas que tendem à introversão, à falta de autoconfiança, ou ao perfeccionismo, pouco se beneficiarão de um conhecimento da estrutura da língua e de suas irregularidades. Pelo contrário, no caso de línguas com alto grau de irregularidade (como o inglês) poderão desenvolver bloqueio que compromete a espontaneidade devido à consciência da alta probabilidade de cometerem erros. Pessoas que tendem à extroversão, a falar muito, de forma espontânea e impensada também pouco se beneficiarão de aprendizagem, uma vez que a função de monitoramento é quase inoperante [...]. Os únicos que se beneficiam de aprendizagem são as pessoas [...] que sabem aplicar a função de monitoramento de forma moderada.
\end{abstract}

De fato existem alunos que somente começam a produzir sentenças próprias (tanto orais quanto escritas) quando têm absoluta certeza que elas estão completamente de acordo com as regras (gramaticais, fonéticas, ortográficas, morfossintáticas etc.) que aprenderam. Esses aprendizes normalmente passam por um período de silêncio ${ }^{7}$ muito longo e têm muita dificuldade de se expor em atividades orais durante as aulas. Embora o período de silêncio afete todos os alunos, o foco excessivo na forma pode aumentar significativamente esse período em alguns alunos. A preocupação com a correção lingüística pode gerar insegurança e frustração, além de um discurso menos fluido (ou seja, a produção é constantemente monitorada). Por outro lado, há aqueles que raramente se corrigem ou mantêm o foco na forma ao produzir sentenças. Essa postura faz com que o aluno apresente mais fluência e atinja melhores níveis de desempenho oral, mas dificulta a correção lingüística. Portanto, possivelmente alcançará melhores resultados o aluno que souber dosar a utilização do Monitor. Se bem seja difícil controlar o uso do Monitor, ou seja, utilizá-lo adequadamente, é aconselhável que o professor, após observação acurada de seus alunos, detecte quais são os que utilizam raramente o monitor e proponha práticas que exijam certo conhecimento formal da língua. Por outro lado, ao reconhecer alunos que utilizam o Monitor em demasia, o professor pode preparar atividades que favoreçam o uso espontâneo da língua alvo, o improviso e a necessidade de uma linguagem mais fluente.

\title{
A hipótese da Ordem Natural
}

Esta hipótese está diretamente relacionada à aquisição e não à aprendizagem. Krashen supõe que há uma ordem previsível na aquisição de estruturas gramaticais da língua estrangeira, da mesma forma que existe uma ordem na aquisição de regras da língua materna, ou seja, algumas regras são internalizadas antes que outras. No entanto, essa ordem não é necessariamente a mesma na aquisição da língua materna e na aquisição da língua

7 O conceito "período de silêncio" será abordado novamente mais adiante. 
CALLEGARI - Reflexões sobre o modelo de aquisição de segundas línguas...

estrangeira. Para o lingüista, essa seqüência não é determinada pela simplicidade/ complexidade da regra em questão e ocorre independentemente da ordem seguida no seu estudo durante as aulas (1985:1).

Numa tentativa de validar as idéias acima, Krashen cita pesquisas anteriores feitas por Dulay e Burt (1974) que estudaram a ordem de aquisição de morfemas gramaticais em crianças de cinco a oito anos que aprendiam Inglês como língua estrangeira. Esses autores chegaram a um ranking de morfemas de acordo com os dados obtidos. No entanto, segundo McLaughlin (1987:32), como esse estudo não era longitudinal, os resultados não se referiam à ordem de aquisição dos morfemas em cada criança, mas às estruturas que foram usadas adequadamente por elas mais vezes. Estes resultados não constituiriam, portanto, um argumento que comprovasse a hipótese de Krashen. Além disso, é extremamente difícil reconhecer quando um morfema foi realmente adquirido. O fato de um falante usá-lo adequadamente num contexto específico não significa que ele o usará com propriedade em outras situações.

Outro fator a ser considerado é que, segundo alguns estudos como os de Hakuta e Cancino (1977 apud McLAUGHLIN 1987:32) e McLaughlin (19849 apud McLAUGHLIN 1987:33), a ordem de aquisição de morfemas pode variar de acordo com a língua materna de cada aprendiz, dependendo do grau de diferenças entre a LM e a LE que está sendo aprendida. Alunos cuja LM não apresenta diferenças entre o artigo definido e o indefinido (alunos coreanos, por exemplo) tardarão mais a aprender essa diferenciação em uma língua como o Inglês do que alunos cuja LM apresenta esse contraste (alunos brasileiros, por exemplo). Dessa forma, a premissa de que há uma ordem constante e invariável na aquisição de determinadas estruturas não parece se concretizar na totalidade dos casos. O próprio Krashen reconhece que existem variações individuais (1985:21), mas afirma que esse fato não chega a comprometer sua hipótese já que existem fortes indícios de que determinadas regras são adquiridas antes de outras. Já para McLaughlin (1987:35), o único mérito da hipótese é postular que algumas coisas são aprendidas antes de outras, mas não sempre, o que não a torna completamente válida.

\section{IMPLICAÇÕES EM SALA DE AULA}

Se a hipótese de Krashen estiver correta, existe uma ordem comum de aquisição de estruturas da LE que está sendo estudada, independentemente da idade do aprendiz, de sua LM, de seu tempo de exposição à língua-alvo, etc. Além disso, essa ordem de aquisição ocorre automaticamente se o aluno estiver exposto a mostras significativas da LE, independentemente da ordem de apresentação seguida pelo professor em sala de aula.

${ }^{8}$ HAKUTA, K.; CANCINO, H. Trends in second-language acquisition research. Harvard Educational Review 47, p. 294-316, 1977.

9 McLAUGHLIN, B. Second-language acquisition in childhood. Volume 1: preschool children. Hillsdale, NJ, Lawrence Erlbaum, 1984. 
Entretanto, uma vez que pudesse ser determinada essa suposta ordem, os professores que preparassem seus cursos de acordo com tal seqüência obteriam melhores resultados do que os que se afastassem dessa organização? O questionamento sobre quais estruturas devem ser ensinadas antes de outras não é recente. Não apenas os professores, mas também e sobretudo grande parte dos materiais didáticos seguem uma seqüência de conteúdos que pode ser considerada arbitrária. Tomemos por exemplo o ensino dos tempos verbais de línguas como o português, o espanhol ou o francês. Parte-se, nas aulas iniciais (na maioria dos livros didáticos), dos verbos "ser" e "estar" no presente do indicativo; em seguida passa-se aos verbos regulares no presente do indicativo; seguem-se os irregulares, os tempos do pretérito do indicativo, o futuro do indicativo, presente, pretérito e futuro do subjuntivo e em algum momento apresenta-se o imperativo. Onde está a lógica desse seqüenciamento? Se tomarmos como base a aquisição de língua materna, seguramente a ordem encontrada não será essa. Seria este um dos motivos pelo qual o ensino formal de línguas é pouco eficiente? Para Krashen, não. Muito mais relevante do que a ordem de apresentação dos conteúdos é o oferecimento, por parte do professor, de quantidade suficiente de mostras da língua-alvo que permitam aos alunos a aquisição de novas estruturas. Esta é a base da próxima hipótese do modelo.

\section{A hipótese do Insumo}

Trata-se do eixo de toda a teoria de Krashen. Para ele, a aquisição de uma segunda língua somente ocorrerá se o aprendiz estiver exposto a mostras da língua meta (insumo) que estejam um pouco além do seu nível atual de competência lingüística. Krashen define o nível atual de cada aprendiz como i e o insumo ideal a ser-lhe oferecido como $i+1$. As novas estruturas, o vocabulário desconhecido e as regras gramaticais seriam adquiridos através do contexto em que fossem apresentados, informações extralingüísticas, conhecimento de mundo e o conhecimento lingüístico adquirido pelo aprendiz anteriormente.

$\mathrm{O}$ fato de que dificilmente dois alunos estejam iguais em $i$ não parece ser um problema para Krashen. Segundo ele (1985:2), o professor não precisa esforçar-se para oferecer as próximas estruturas (hipótese da Ordem Natural) a seus alunos: isso ocorrerá automaticamente se eles receberem quantidade suficiente de insumo compreensível.

De acordo com Krashen (1985:2) a hipótese do insumo gera duas importantes afirmações:

a) a fala é resultado da aquisição e não a sua causa e, portanto, não pode ser ensinada diretamente, mas "emerge" como resultado da competência construída via insumo compreensível;

b) se o insumo é compreendido e suficiente, a gramática necessária é automaticamente fornecida.

Para Krashen, a hipótese do insumo é sustentada por dez evidências: 
CALLEGARI - Reflexões sobre o modelo de aquisição de segundas línguas...

1) A FALA MATERNA (caretaker): a fala comumente simplificada que é dirigida às crianças ao adquirirem sua língua materna funciona, segundo o autor, como um facilitador no processo de aquisição. Uma vez que a criança está permanentemente exposta a esse insumo, cuja compreensão é auxiliada por recursos extralingüísticos como gestos, por exemplo, é fornecido a ela $i+1$ e, dessa forma, a aquisição se processa. À medida que a criança e sua competência lingüística se desenvolvem, a complexidade do insumo aumenta. Numa transposição à aquisição de língua estrangeira, para que se obtenham também resultados satisfatórios, a fala utilizada pelo professor deve seguir o mesmo caminho, ou seja, partir de estruturas menos complexas e avançar gradativamente de acordo com o estágio lingüístico dos alunos.

2) O PERÍODO DE SILÊNCIO: trata-se do fenômeno que ocorre principalmente (mas não apenas) com crianças que aprendem uma língua estrangeira em situação de imersão e que passam um longo período de tempo em silêncio, produzindo apenas um pequeno número de sentenças da LE. Esse período pode durar meses até que a criança consiga comunicar-se adequadamente no novo idioma. Para Krashen, esse silêncio é decorrência do processo de construção de competência, via compreensão de insumo. Com adultos que aprendem uma língua estrangeira ocorreria o mesmo: há um período inicial no qual o aprendiz, a partir do insumo compreensível que lhe é oferecido em cada momento, constrói as bases de sua competência comunicativa na língua-alvo. Para o autor, durante esse período, não é aconselhável que o professor estimule a produção criativa. Ao ser solicitado a falar sem estar preparado, o aluno pode fazer uso inadequado de sua língua materna numa tentativa de suprir as faltas de um processo de construção de competência inacabado.

3) DIFERENÇAS ETÁRIAS: segundo Krashen, dados comprovam que crianças são geralmente superiores aos adultos na aprendizagem de LE a longo prazo; no entanto, adultos a aprendem mais rapidamente. Isso se deve ao fato de que aprendizes mais velhos obtêm mais quantidade de insumo compreensível, enquanto que aprendizes mais jovens são melhores a longo prazo porque apresentam um filtro afetivo baixo. (Este tema será novamente abordado na discussão da hipótese seguinte).

4) O EFEITO DA INSTRUÇÃO FORMAL: alunos que aprendem a língua estrangeira em contextos formais teriam melhores ou mais fracos resultados do que aprendizes que vivem em ambiente de total imersão no idioma? Para Krashen, essa questão pode ser respondida com base na hipótese do insumo: as aulas de LE seriam mais eficientes para alunos iniciantes, que freqüentemente têm muita dificuldade de compreensão ao serem expostos a um ambiente de imersão. Por outro lado, o ensino formal traria menos benefícios a alunos de níveis avançados que já teriam condições de compreender um input mais complexo.

5) O EFEITO DA EXPOSIÇÃO: para Krashen, a exposição à língua estrangeira somente trará benefícios ao aprendiz se contiver insumo compreensível. Portanto, nem sempre grande quantidade de insumo ou grande tempo de exposição ao input garantem bons resultados.

6) INSUFICIÊNCIA DE INPUT COMPREENSÍVEL: Para Krashen, o fato de um aprendiz não ser exposto a suficiente insumo compreensível compromete a aquisição. $\mathrm{O}$ 
Trab.Ling.Aplic., Campinas, 45(1) - Jan./Jun. 2006

autor cita pesquisas feitas com crianças filhas de pais surdos e que, portanto, não receberam quantidade suficiente de insumo que lhes permitisse aquisição. Essas crianças apresentaram um grande atraso na aquisição da língua, sanado posteriormente ao conviverem com outras crianças.

7) PESQUISA DE COMPARAÇÃO DE MÉTODOS: Segundo Krashen (1985:14), foram realizadas algumas pesquisas (embora não especificadas pelo autor) que compararam a eficácia de métodos de base gramatical e métodos de base áudio-oral. Os resultados revelaram que havia pouca diferença entre eles. Para o autor, isso se deve ao fato de que nenhuma das duas metodologias é capaz de oferecer suficiente input compreensível aos aprendizes. Pesquisas mais recentes apontam que outros métodos, como o Resposta Física Total (Asher 1982), o Método Natural (Krashen; Terrell 1983) e a Sugestopedia (Lozanov 1978) são mais eficientes porque apresentam duas características essenciais para a aquisição de uma LE: fornecem grande quantidade de input compreensível e propiciam um ambiente de baixa ansiedade.

8) PROGRAMAS DE IMERSÃO: para Krashen, o êxito de programas canadenses de imersão em LE evidencia a hipótese do input. Através desses programas, alunos de escolas públicas cuja LM é o Inglês passam a estudar, durante determinado período de tempo, as disciplinas curriculares na LE, no caso, em Francês. Ao final do período, os alunos apresentam ótimos níveis de proficiência em LE. Para Krashen esse fato se explica porque:

- os alunos tiveram acesso a grande quantidade de input;

- o input fazia-se compreensível pois era sempre apresentado em contexto;

- como os alunos eram avaliados apenas por seus conhecimentos nas disciplinas, e não pelo seu conhecimento lingüístico, o foco encontrava-se sempre na mensagem e não na forma, propiciando a aquisição.

9) O SUCESSO DE PROGRAMAS BILÍNGÜES: para Krashen, a hipótese do input também explicaria o sucesso de determinados programas de educação bilíngüe e o fracasso de outros. Seriam eficientes os programas bilíngües que desenvolvessem no aprendiz sólidos conhecimentos também em sua LM, o que possibilitaria que ele soubesse utilizar a língua (seja ela LM ou LE) para aprender e discutir idéias abstratas, o que facilitaria a compreensão do input. Por outro lado, seriam ineficientes os programas que utilizam a tradução como recurso principal em suas aulas, já que dessa forma não existe "negociação de significado" e o aprendiz não se preocupa em entender mensagens em LE uma vez que elas serão rapidamente traduzidas à sua $\mathrm{LM}$.

10) A HIPÓTESE DA LEITURA: segundo Krashen, estudos ${ }^{10}$ comprovam que os alunos de LE que apresentam melhores performances na modalidade escrita da língua são aqueles que exercitam a leitura por interesse próprio. $\mathrm{O}$ autor postula, assim, que a competência escrita é decorrente de leituras auto-motivadas, que serviriam de input, da mesma forma que a competência oral é construída através da exposição a input compreensível.

${ }^{10} \mathrm{O}$ autor não especifica a quais estudos se refere. 
CALLEGARI - Reflexões sobre o modelo de aquisição de segundas línguas...

McLaughlin (1987) tece extensas críticas à hipótese do insumo. Apresentamos aqui as principais:

a) É extremamente difícil definir o nível lingüístico $(i)$ no qual se encontra um aluno. Conseqüentemente, não será simples definir $i+1$, o que já torna a hipótese bastante comprometida;

b) A teoria não consegue definir quando um insumo é compreensível e quando não o é.

c) Os dez fatores apontados por Krashen como evidências da hipótese do insumo na verdade não poderiam ser considerados como tais, uma vez que se trata de fenômenos que podem ser explicados à luz da hipótese e não o contrário. Em outras palavras, as evidências da hipótese confirmam-se exclusivamente no âmbito da hipótese, mas não provam que ela seja verdadeira.

d) $\mathrm{O}$ mero fato de que alguns aprendizes se calem por certo período de tempo ao entrar em contato com a LE não evidencia a hipótese do insumo. Outros fatores, não relacionados diretamente à hipótese do insumo, deveriam ter sido levados em consideração, como a ansiedade, as diferenças individuais etc.

e) Ao afirmar que adultos aprendem a LE mais rapidamente que as crianças, Krashen torna contraditória a idéia de que a fala simplificada (caretaker) utilizada com as crianças seja um facilitador do processo. Se essa linguagem simplificada é ideal para que se chegue a $i+1$, então as crianças deveriam aprender a LE mais rapidamente. Além disso, Krashen credita o fato de os adultos aprenderem mais rapidamente a LE apenas à sua maior facilidade de compreensão de insumo. No entanto, McLaughlin aponta outros fatores possíveis: maior capacidade mnemônica, a necessidade de falar sobre assuntos mais complexos e a habilidade em beneficiar-se da correção gramatical. Acrescentaríamos aqui as motivações que levam um adulto a aprender o idioma, muitas vezes não presentes nas crianças e a própria experiência enquanto aprendizes em geral, e aprendizes de línguas estrangeiras em particular, o que implica maior consciência - ou melhor uso - de estratégias de aprendizagem e de comunicação.

f)A questão de como estruturas desconhecidas são adquiridas é bastante complexa e não se limita à existência de recursos extralingüísticos. Tais recursos podem ser eficientes na compreensão de aspectos semânticos da língua mas dificilmente serão suficientes para esclarecer questões sintáticas, por exemplo.

g) Não há nenhuma menção na teoria quanto ao processo interno que explique como o aprendiz de uma LE passa do nível de compreensão à aquisição da língua.

\section{IMPLICAÇÕES EM SALA DE AULA}

Além de algumas implicações já mencionadas, é necessário enfatizar a dificuldade do professor em definir o nível lingüístico (i) dos alunos em sala de aula para que possa chegar ao conceito de $i+1$. O professor trabalha sempre inferindo a competência lingüística de seus alunos através da análise de sua performance, o que dificilmente lhe dará garantias 
de que o nível observado é equivalente ao real nível lingüístico do aluno. Ainda que fosse possível chegar a esse nível individual de competência lingüística, muito provavelmente não haveria dois alunos no mesmo patamar. Como oferecer então $i+1$ a todos? Se essa questão não for resolvida, a hipótese realmente não terá, em termos práticos, validade alguma.

Outro ponto que merece atenção é a questão da "linguagem simplificada" que deve ser utilizada pelo professor quando seus alunos ainda estão em níveis básicos da língua. Ao tornar a língua menos complexa, o professor corre o risco de utilizar uma linguagem não real, simulada e que, portanto, não aportará insumo de qualidade.

\section{A QUINTA HIPÓTESE DO MODELO: O FILTRO AFETIVO}

Em sua teoria, Krashen atribui aos fatores afetivos uma importância considerável uma vez que, para ele, esses fatores estão diretamente relacionados tanto ao processo de aquisição/aprendizagem de uma segunda língua quanto aos resultados obtidos ao longo e ao final desse processo. A desmotivação do aprendiz, a alta ansiedade e a baixa autoconfiança são elementos que podem, segundo o pesquisador, dificultar a aquisição. Por outro lado, a aquisição será facilitada se houver condições psicológicas favoráveis (motivação, baixa ansiedade e auto-confiança elevada).

Embora do nosso ponto de vista esta hipótese seja de grande relevância, Krashen dispensou-lhe um tratamento bastante sucinto. Conforme visto na hipótese anterior, estar exposto a um input compreensível é condição necessária para que um indivíduo adquira uma língua estrangeira. No entanto, segundo Krashen, apenas a exposição ao input não é suficiente, é necessário que o aprendiz esteja afetivamente predisposto a recebê-lo. Para o autor, nem todo input consegue transformar-se em aquisição devido à existência do que ele denomina "filtro afetivo" definido como "o bloqueio mental que impede os aprendizes de utilizar completamente o input compreensível recebido para a aquisição da linguagem" (Krashen 1985:3) $)^{11}$

Isso significa que se o filtro afetivo estiver alto, "o aprendiz pode entender o que ouve e lê, mas o input não chegará ao LAD (Dispositivo de Aquisição da Linguagem)."12 (Krashen 1985:3)

Para o lingüista, os alunos possuem um filtro afetivo baixo (e portanto adquirem uma segunda língua com maior facilidade e maior eficácia) quando não se preocupam com a possibilidade de insucesso na aquisição da língua e quando se consideram membros potenciais do grupo que fala a língua-alvo. Por outro lado, um aluno com filtro afetivo alto (desmotivado, com grande ansiedade e baixa autoconfiança), ainda que exposto

${ }^{11}$ Original: "The 'affective filter' is a mental block that prevents acquirers from fully utilizing the comprehensible input they receive for language acquisition."

${ }^{12}$ Original: "When it is 'up', the acquirer may understand what he hears and reads, but the input will not reach the $L A D$." 
CALLEGARI - Reflexões sobre o modelo de aquisição de segundas línguas...

intensamente à língua estrangeira, não atingirá um nível lingüístico semelhante ao de um falante nativo.

A situação ideal para aquisição seria então, segundo Krashen (1985:4), a existência de um filtro afetivo baixo, que faria com que o aprendiz estivesse tão envolvido na mensagem que temporariamente esquecesse que está ouvindo ou lendo outra língua.

Para Krashen, a existência do filtro afetivo é a principal explicação para as diferenças individuais de aprendizagem, sobretudo entre crianças e adultos. Para o autor, embora possa existir desde a infância, o filtro afetivo ganha força durante a puberdade e nunca mais atingirá um nível muito baixo novamente.

Embora Krashen tenha percebido a relevância dos aspectos afetivos no processo de aquisição de uma língua estrangeira, sua teoria não avança na discussão dessa hipótese e deixa ainda bastantes lacunas. O autor não chega nem mesmo a definir completamente quais seriam os fatores responsáveis pelo suposto bloqueio que dificulta a aquisição. Em seu estudo, Krashen cita apenas três aspectos como possíveis causas de um filtro afetivo alto: a desmotivação, a baixa autoconfiança e a ansiedade. Trata-se de três conceitos muito amplos, complexos e distintos que, ao nosso ver, merecem ainda melhores análises e que não podem simplesmente ser analisados desde a mesma perspectiva.

Para McLaughlin (1987), não há dúvida que os fatores afetivos desempenham um papel importante na aprendizagem de segundas línguas. Suas críticas com relação à hipótese do filtro afetivo se relacionam:

1. AO CARÁTER NÃO INOVADOR DAS IDÉIAS PROPOSTAS. Para o crítico, se já existem numerosos estudos envolvendo diferenças individuais na aprendizagem de línguas estrangeiras, não há necessidade de criar-se um conceito como o do filtro afetivo para tentar explicar que certos fatores psicológicos interferem no processo de aquisição.

2. À FALTA DE DEFINIÇÃO DE DETERMINADOS CONCEITOS. McLaughlin toca aqui num ponto de extrema importância que não é esclarecido por Krashen: se o filtro afetivo é um mecanismo que apenas restringe e limita a entrada de input, e se apresentará um filtro afetivo alto o indivíduo que estiver desmotivado, a teoria equipara os conceitos de indiferença e alta motivação.

3. À FALTA DE EXPLICAÇÃO DO REAL FUNCIONAMENTO DO FILTRO AFETIVO. McLaughlin (1987:54) argumenta que a teoria de Krashen ainda não foi capaz de precisar como opera efetivamente o filtro afetivo, ou seja, como esse filtro determina quais "partes da língua" atingirão ou não o dispositivo de aquisição da linguagem. O crítico cita como exemplo um aluno de alemão que tenha uma pronúncia quase perfeita, exceto pelos fonemas /r/ e /1/. Por que o filtro impediu a aquisição desses sons e não de outros? O que faz com que um aprendiz retenha determinadas palavras ou regras e não assimile outras? Não há menção no modelo de como funciona esse critério de seleção.

4. ÀS IMPLICAÇÕES METODOLÓGICAS DE COMPROVAÇÃO EMPÍRICA. É extremamente difícil demonstrar através de pesquisas qualquer relação entre fatores psicológicos e aprendizagem de línguas, uma vez que as variáveis envolvidas no processo dificilmente conseguirão ser isoladas. 
Aparte as críticas de McLaughlin, há ainda outros pontos no modelo de Krashen (1985:4) que merecem atenção por sua debilidade. O autor chega a afirmar: "Quando o filtro é 'baixo' e um input apropriado e compreensível é apresentado (e compreendido), a aquisição é inevitável." ${ }^{13} \mathrm{Se}$, por um lado, os bloqueios afetivos dificultam a aquisição de uma LE (e de fato assim o parece), por outro, a falta de bloqueios ou bloqueios fracos por si só não garantem o resultado do processo. "Inevitável" parece ser uma palavra muito forte e até mesmo determinista, já que há inúmeras variáveis que interferem no complexo processo de aquisição de línguas estrangeiras e que foram, nessa afirmação, totalmente rechaçadas.

Mais adiante, Krashen equipara a aquisição de LE à aquisição de LM, valendo-se da afirmação de Noam Chomsky de que o aprendiz "não tem razão" para adquirir a língua materna. Para Krashen, assim como para Chomsky, "o órgão mental da linguagem se desenvolverá inevitavelmente, independentemente da vontade do aprendiz." (Chomsky 1975:71 ${ }^{14}$, apud KRASHEN 1985:4). Em se tratando do processo de aquisição/ aprendizagem de línguas estrangeiras, estas afirmações parecem equivocadas. Sabe-se o quão difícil é o processo de aquisição de uma LE e quantas consideráveis diferenças há entre a aquisição de uma LM e de uma LE. Pode-se dizer que a motivação, assim como outros fatores psicológicos (auto-estima, autoconceito lingüístico, autoconfiança), afetam em maior grau a aprendizagem de segundas línguas/línguas estrangeiras e são variáveis que diferenciam a aquisição da língua materna da aquisição de outras línguas, principalmente quando essas novas línguas são aprendidas/adquiridas em idade posterior à infância. Os fatores que levam o indivíduo a adquirir a sua língua materna são bem diferentes das motivações necessárias para aprendizagem de uma língua estrangeira. Aqui podem ser incluídos o desejo de se comunicar com outras culturas, uma necessidade profissional, um desejo pessoal etc., que não estão em jogo quando se adquire a língua materna.

Adotar uma posição cognitivista de trabalho, como faz Krashen, não significa necessariamente igualar os processos de aquisição de LM e LE. Ambos os processos apresentam semelhanças e diferenças e pode-se afirmar que os fatores afetivos incluem-se justamente nas diferenças.

Além de prejudicar a aquisição, dificultando a entrada de input, há filtros que podem também afetar o output ${ }^{15}$, criando uma grande distância entre a competência e o desempenho ${ }^{16}$ do aprendiz em LE (Krashen 1985:45). Embora Krashen não relacione diretamente esses filtros do output com fatores afetivos, torna-se difícil supor que a produção do aprendiz não seja afetada por questões dessa ordem, levando-o a diferentes níveis de desempenho que estarão subordinados à variação de tais fatores. Isso equivale a dizer que alunos que adquirem uma língua estrangeira podem não conseguir usá-la adequadamente se o filtro afetivo responsável pelo output estiver alto.

\footnotetext{
${ }^{13}$ Original: "When the filter is 'down' and appropriate comprehensible input is presented (and comprehended), acquisition is inevitable”.

${ }^{14}$ CHOMSKY, N. Reflections on language. New York, Pantheon Books, 1975.

${ }^{15}$ Output: termo para utilizado para designar a produção criativa do aluno/aprendiz.

${ }^{16}$ Para os gerativistas, a competência é o conhecimento mentalizado, abstrato, que os falantes possuem da língua. Já o desempenho é o uso que cada indivíduo faz desse conhecimento.
} 
CALLEGARI - Reflexões sobre o modelo de aquisição de segundas línguas...

Efeito semelhante podemos observar no desempenho de falantes em sua LM, que sofrerá variações relacionadas a fatores afetivos, como a motivação para um determinado discurso, a ansiedade, o autoconceito lingüístico, a auto-estima, entre outros.

Conforme apontado por McLaughlin, talvez o grande nó desta questão seja de ordem metodológica. O filtro afetivo engloba uma série de fatores que até o momento não foram completamente descritos. Esses fatores são inerentes ao indivíduo, inconstantes, mutáveis e idiossincráticos. De indivíduo para indivíduo as variações são ainda maiores e mais complexas, ou seja, algumas situações motivam um determinado indivíduo hoje, mas não o motivarão amanhã, por razões bastante diversas e variáveis. Além disso, o que provoca ansiedade em um sujeito não são, necessariamente, os mesmos fatores que provocam ansiedade em outro. Isso faz com que as pesquisas empíricas nessa área sejam raras e uma comprovação da hipótese do Filtro Afetivo ainda pareça distante. O modelo de Krashen sofre suas maiores críticas no que se refere justamente à comprovação empírica de suas hipóteses. Parece que tal dificuldade afeta diretamente esta quinta hipótese.

Há ainda que se considerar ainda um importante contraponto à hipótese do filtro afetivo de Krashen: os fatores afetivos e a aprendizagem apresentam uma correlação direta apenas até certo ponto, isto é, nem sempre quanto maior a motivação maior a aprendizagem. Auto-estima superelevada e motivação em excesso, por exemplo, podem comprometer o processo, assim como uma baixíssima ansiedade pode dificultar o interesse pela aprendizagem.

No entanto, todas essas dificuldades de caracterização e conceituação não nos impedem de considerar o papel importante desempenhado pela teoria de Krashen nos estudos sobre aquisição de línguas estrangeiras. Vimos que o modelo contém falhas, não apenas por carecer de comprovação empírica, mas por apresentar imprecisões e algumas contradições internas. Não obstante, o autor coloca em evidência novos conceitos que passaram a ser amplamente discutidos e estudados ao longo das últimas décadas e que aportam, conforme visto ao longo do texto, significativas contribuições à didática de línguas.

\section{REFERÊNCIAS BIBLIOGRÁFICAS}

CALLEGARI, M. O. V. (2004). Saborear para saber: diferentes olhares sobre a motivação em sala de aula - um estudo com alunos e professores de espanhol do Ensino Médio. São Paulo, FEUSP, dissertação de Mestrado.

DULAY, H. C.; M. K. BURT. (1974). Natural sequences in child second language acquisition. Language Learning 24, p. 37-53.

KRASHEN, S. (1985). The Input Hypothesis: issues and implications. 4.ed. New York, Longman.

LLOBERA, M. et al. (1995). Competencia comunicativa. Madrid, Edelsa.

McLAUGHLIN, B. (1987). Theories of second language learning. London, Arnold. 
Trab.Ling.Aplic., Campinas, 45(1) - Jan./Jun. 2006

ROMEO, K. Krashen and Terrell's "Natural Approach". Disponível em: http://www.stanford.edu/ hakuta/ LAU/ICLangLit/NaturalApproach.htm. Acesso em: 14 out. 2003.

SCHÜTZ, R. Stephen Krashen's Theory of Second Language Acquisition. 2002. Disponível em: 〈http:// www.sk.com.br/sk-krash.html>. Acesso em: 14 out. 2003. 